\title{
Decadal variations in estimated surface solar radiation over Switzerland since the late 19th century
}

\author{
A. Sanchez-Lorenzo and M. Wild \\ Institute for Atmospheric and Climate Science, ETH Zurich, Zurich, Switzerland \\ Correspondence to: A. Sanchez-Lorenzo (arturo.sanchez@env.ethz.ch) \\ Received: 27 March 2012 - Published in Atmos. Chem. Phys. Discuss.: 25 April 2012 \\ Revised: 14 August 2012 - Accepted: 7 September 2012 - Published: 25 September 2012
}

\begin{abstract}
Our knowledge on trends in surface solar radiation (SSR) involves uncertainties due to the scarcity of long-term time series of SSR, especially with records before the second half of the 20th century. Here we study the trends of all-sky SSR from 1885 to 2010 in Switzerland, which have been estimated using a homogenous dataset of sunshine duration series. This variable is shown to be a useful proxy data of all-sky SSR, which can help to solve some of the current open issues in the dimming/brightening phenomenon. Allsky SSR has been fairly stable with little variations in the first half of the 20th century, unlike the second half of the 20th century that is characterized also in Switzerland by a dimming from the 1950s to the 1980s and a subsequent brightening. Cloud cover changes seem to explain the major part of the decadal variability observed in all-sky SSR, at least from 1885 to the 1970s; at this point, a discrepancy in the sign of the trend is visible in the all-sky SSR and cloud cover series from the 1970 s to the present. Finally, an attempt to estimate SSR series for clear-sky conditions, based also on sunshine duration records since the 1930s, has been made for the first time. The mean clear-sky SSR series shows no relevant changes between the 1930s to the 1950s, then a decrease, smaller than the observed in the all-sky SSR, from the 1960s to 1970 s, and ends with a strong increase from the 1980s up to the present. During the three decades from 1981 to 2010 the estimated clear-sky SSR trends reported in this study are in line with previous findings over Switzerland based on direct radiative flux measurements. Moreover, the signal of the El Chichón and Pinatubo volcanic eruption visible in the estimated clear-sky SSR records further demonstrates the potential to infer aerosol-induced radiation changes from sunshine duration observations.
\end{abstract}

\section{Introduction}

Solar radiation incident at the Earth's surface, also known as surface solar radiation (SSR), is the fundamental source of energy in the climate system, and consequently the source of life on our planet, due to its central role in the surface energy balance and for processes such as evaporation and the water cycle or plant photosynthesis (e.g. Wild, 2009, 2012). Observational studies show that SSR has not been stable over the last decades, but underwent significant multi-decadal variations since the second half of the 20th century. Particularly, a widespread reduction of SSR from the 1950s to the 1980s has been well established and documented (Ohmura and Lang, 1989; Gilgen et al., 1998; Liepert, 2002; Stanhill and Cohen, 2001), and since the 1980s a reversal in this trend has been observed at many of the observation sites (Wild et al., 2005; Ohmura, 2009; Philipona et al., 2009). This decrease and increase in SSR has been coined as global dimming and brightening, respectively.

The causes of this phenomenon are currently not fully understood, although changes in the transparency of the atmosphere due to changes in clouds or anthropogenic aerosols are considered as the main factors explaining these trends (Stanhill and Cohen, 2001; Wild, 2009, 2012). Regarding clouds, it has been suggested that the dimming (brightening) period may be linked to an increase (decrease) in cloud cover detected in some regions (Trenberth et al., 2007; Wild, 2009). It must be noted, however, that this fact is not always obvious due to a disagreement in the trends of both variables found in other studies (e.g. Kaiser, 2000; Norris and Wild, 2007, 2009; Brunetti et al., 2009; Sanchez-Lorenzo et al., 2009; Wild, 2009). Equally, a systematic assessment of cloud cover changes using satellite observations is only possible 
since the 1980s, which however show large inconsistencies with respect to the trends for the different products currently available (Cermak et al., 2010). Consequently, the surfacebased observations of cloudiness are the main source of data to study their trends before the 1980 s; e.g. to assess the role of the clouds during the dimming period.

Therefore, changes in anthropogenic aerosol emissions are currently considered to be the most likely cause of the dimming/brightening phenomenon. This is supported by the fact that observed decadal changes in anthropogenic aerosol emissions are in line with the trends in SSR (e.g. Streets et al., 2006; Wild, 2009; Cermak et al., 2010; Folini and Wild, 2011). These evidences have also been supported by changes in SSR under clear-sky conditions since the 1970s (e.g. Wild et al., 2005; Norris and Wild, 2007, 2009; Ruckstuhl et al., 2008; Folini and Wild, 2011), pointing to the prominent role of atmospheric aerosols (i.e. aerosol direct effects) in the explanation of the observed SSR trends.

However, both global dimming and brightening still have major uncertainties, as pointed out by Wild $(2009,2012)$. For example there is lack of SSR data available before the 1950s (widespread measurements of SSR were only initiated in 1957/58 within the framework of the International Geophysical Year), as well as studies focusing on SSR trends under clear-sky conditions, which requires high temporal resolution of SSR data together with collocated cloud cover information. In fact, although the major gaps in direct observations are located in developing areas such as Africa or Central and South America, still there is a lack of long-term series even over the regions with the highest density of data (e.g. Europe). Thus, for example, in the Global Energy Balance Archive (GEBA) (Gilgen et al., 1998) currently there are only 4 all-sky SSR series in Switzerland with data before the 1960s. Regarding clear-sky SSR trends in Switzerland, the studies published at present are limited to the period after the 1980s (Ruckstuhl et al., 2008). Equally, there is a lack of a data quality assessment in the SSR series, which often contain spurious data and temporal inhomogeneities (e.g. Shi et al., 2008; Sanchez-Lorenzo et al., 2011; Tang et al., 2011). Specifically, Tang et al. (2011) recently pointed to deficiencies in the SSR series over China regarding the homogeneity of the series before 1994, which were solved estimating the SSR variations since the 1960s by using different parameters such as standard meteorological observations, the Angström turbidity coefficient, and the thickness of the ozone layer.

Overall, to overcome these limitations in the dimming/brightening issue, the analysis can be supported with the help of other related climate variables, or proxy data, such as sunshine duration (SD), cloudiness or visibility, which are much more widely available (Wild, 2009, 2012). Specifically, $\mathrm{SD}$ is defined as the time span, usually expressed in number of hours, that direct solar radiation exceeds a certain threshold (usually taken at $120 \mathrm{~W} \mathrm{~m}^{-2}$ ). The measurements of this element were initiated as early as in the late 19th century (Pallé and Butler, 2001; Stanhill, 2003). This variable is con- sidered an excellent proxy measure of direct solar radiation (e.g. Galindo Estrada and Fournier D'Albe, 1960; Stanhill, 1998), as well as of SSR at interannual and decadal scales (e.g. Stanhill, 2003, 2011; Stanhill and Cohen, 2001, 2005, 2008), and plays an important role in the description of the dimming and brightening and their uncertainties (SanchezLorenzo et al., 2009; Wild, 2009, 2012).

On the other hand, a systematic analysis of the relationship between the SD and SSR on regional scales, and the reconstruction of this latter variable since the beginning of the measurements of the former one, is lacking over Europe, as to our knowledge only two previous attempts have been made for the US (Stanhill and Cohen, 2005) and Japan (Stanhill and Cohen, 2008) only for all-sky conditions. Thus, the main objective of our study is to compare a high-quality data set of SD and SSR series in Switzerland in order to quantify the relationship between both variables at interannual and decadal time scales, which can be used to estimate changes of all-sky (clear-sky) SSR since the late 19th century (1930s).

\section{Data}

The data used in this study was obtained from the Swiss Federal Office of Meteorology and Climatology (MeteoSwiss) in Switzerland. It consists of daily records of SD (in hours) and total cloud cover (TCC, in \%) from 17 stations (Table 1). The longest series of these two variables span the 18852010 period, with all these series available after the 1930s. Daily series of SSR (in $\mathrm{W} \mathrm{m}^{-2}$ ) for the 17 stations during the period 1981-2010 are also considered. The series were converted into monthly records by averaging the daily series. When less than 20 days in a month were available we did not compute the monthly value, and the month was considered as missing. Additional homogenous SD monthly series, provided by the HISTALP database (Auer et al., 2007), are used from Austria, Germany, France and Italy (Table 2) in order to support the homogenization of the monthly SD series in Switzerland.

Regarding the SD measurements, the main instrument used from the late 19th century to the 1980s in Switzerland has been the Campbell-Stokes heliograph, which ensures consistency in the instrument due to the robustness of this device (Pallé and Butler, 2002; Stanhill, 2003). However, since the late 1970s and early 1980s all SD measurements have been automated in Switzerland, which might produce breaks in the time series (e.g. Major, 1986; Stanhill and Cohen, 2008). However, these new devices were adjusted to the performance of the Campbell-Stokes recorders after a comparison of both instruments (Baumgartner, 1979; Lindfors and Vuilleumier, 2005; L. Vuilleumier, personal communication, 2011). Nevertheless, the homogeneity of the SD series in Switzerland cannot be a priori ensured, especially before and after the 1980s due to the instrument change. Therefore, extensive homogeneity tests have been applied (see Sect. 3). 
Table 1. Details of the 17 stations over Switzerland used in this study, including the starting year for sunshine duration (SD), total cloud cover (TCC), and surface solar radiation (SSR) measurements at each station.

\begin{tabular}{llllllll}
\hline Station & Long., deg & Lat., deg & Alt., $\mathrm{m}$ & Composite $^{\mathrm{a}}$ & SD & TCC & SSR \\
\hline Basel & 7.58 & 47.54 & 316 & $\mathrm{~N}$ & $1885^{*}$ & 1864 & 1981 \\
Bern & 7.46 & 46.99 & 553 & $\mathrm{Y}(2006)$ & $1886^{*}$ & 1864 & 1981 \\
Chur & 9.53 & 46.87 & 556 & $\mathrm{~N}$ & 1909 & 1931 & 1981 \\
Davos & 9.84 & 46.81 & 1594 & $\mathrm{~N}$ & 1884 & $1901^{\mathrm{b}}$ & 1981 \\
Geneve & 6.13 & 46.25 & 420 & $\mathrm{Y}(1958)$ & $1897^{*}$ & 1865 & 1981 \\
Jungfraujoch & 7.99 & 46.55 & 3580 & $\mathrm{~N}$ & 1938 & 1933 & 1981 \\
La Chaux-de-Fons & 6.79 & 47.08 & 1018 & $\mathrm{~N}$ & $1901^{*}$ & 1901 & 1981 \\
Locarno & 8.79 & 46.17 & 367 & $\mathrm{~N}$ & $1935^{*}$ & 1935 & 1981 \\
Lugano & 8.96 & 46.00 & 273 & $\mathrm{~N}$ & $1885^{*}$ & 1984 & 1981 \\
Luzern & 8.30 & 47.04 & 454 & $\mathrm{~N}$ & $1914^{*}$ & $1931^{\mathrm{b}}$ & 1981 \\
Montana & 7.46 & 46.30 & 1427 & $\mathrm{~N}$ & $1931^{*}$ & $1931^{\mathrm{b}}$ & 1981 \\
Neuchatel & 6.95 & 47.00 & 485 & $\mathrm{~N}$ & $1902^{*}$ & $1901^{\mathrm{b}}$ & 1981 \\
Säntis & 9.34 & 47.25 & 2502 & $\mathrm{~N}$ & 1888 & 1882 & 1981 \\
Schaffhausen & 8.62 & 47.69 & 438 & $\mathrm{~N}$ & 1931 & 1931 & 1981 \\
Scuol & 10.28 & 46.79 & 1304 & $\mathrm{~N}$ & $1931^{*}$ & $1931^{\mathrm{b}}$ & 1981 \\
Sion & 7.33 & 46.22 & 482 & $\mathrm{Y}(1978)$ & 1906 & 1864 & 1981 \\
Zürich & 8.57 & 47.38 & 556 & $\mathrm{~N}$ & $1884^{*}$ & 1864 & 1981 \\
\hline a Indication of composite series (Yes/No) and the year of the station's change. & & & \\
b Davos, Luzen, Montana, Neuchatel and Scuol measurements of TCC are only available until 2005, 2007, 1996, 2006 and 2005, \\
respectively. \\
* Stations considered homogeneous for clear-sky SD series. & & & & & \\
& & & & & &
\end{tabular}

Table 2. Details of the 13 longest SD series in the HISTALP data set used to support the homogeneization of the records in Switzerland, including the starting year of the measurements (source: http://www.zamg.ac.at/histalp/content/view/35/1/index.html).

\begin{tabular}{lllrrrr}
\hline ID & Station & Country & Long., deg & Lat., deg & Alt., m & Starting Year* \\
\hline KLA & Klagenfurt-Flughafen & Austria & 14.32 & 46.65 & 459 & 1884 \\
KRE & Kremsmünster & Austria & 14.13 & 48.06 & 389 & 1884 \\
SON & Sonnblick & Austria & 12.96 & 47.05 & 3105 & 1887 \\
VIA & VillacherAlpe & Austria & 13.67 & 46.60 & 2160 & 1884 \\
GAR & Garmisch-Partenkirchen & Germany & 11.07 & 47.48 & 719 & 1936 \\
HOP & Hohenpeißenberg & Germany & 11.02 & 47.80 & 986 & 1937 \\
MUN & München-Stadt & Germany & 11.55 & 48.17 & 525 & 1936 \\
STU & Stuttgart-Schnarrenberg & Germany & 9.20 & 48.83 & 311 & 1925 \\
ZUG & Zugspitze & Germany & 10.98 & 47.42 & 2962 & 1901 \\
BES & Besancon & France & 5.99 & 47.25 & 307 & 1894 \\
LYO & Lyon-Bron airport & France & 4.94 & 45.72 & 198 & 1881 \\
NAN & Nancy-Essey airport & France & 6.22 & 48.69 & 212 & 1930 \\
TRI & Trieste & Italy & 13.77 & 45.65 & 67 & 1886 \\
\hline
\end{tabular}

* Series are available until 2007.

For the TCC series, all records are estimated by traditional visual observations made by observers. Daily TCC means are obtained from the average of at least 3 observations per day taken at around 06:00, 12:00 and 18:00 UTC. Possible inhomogeneities can be present in the series due to changes in observation times or observers (e.g. Sanchez-Lorenzo et al., 2012).

In order to study clear-sky conditions for SD and SSR data, only the days with daily mean TCC equal or less than $25 \%$ (or 2 oktas) have been selected (e.g. Sanchez-Lorenzo et al., 2009; Xia, 2010; Wang et al., 2012). Similar results are obtained if a $12.5 \%$ ( 1 okta) threshold is considered (not shown), but due to the low number of days that fulfill these requirements a wider range is preferred in order to obtain more robust statistics. For clear-sky SD and SSR, the monthly values were computed if at least one clear-sky day was available in this month. 


\section{Homogenization of the dataset}

The homogeneity of each of the 17 SD and TCC monthly data was checked by means of the Standard Normal Homogeneity Test (SNHT, Alexanderson and Moberg, 1997). Our procedure rejects the a priori existence of homogenous reference series and consists of testing each of the 17 series against other series, normally in subgroups of preferentially the 3-5 highest correlated series. For the SD homogenization some stations in the surroundings of Switzerland have been used (Table 2), as previously detailed, especially to check possible breaks around the 1980s as a result of the instrumentation change. The results confirm that only one SD series (Säntis) can be considered inhomogeneous, although due to breaks before the 1980s. On the other hand, 5 TCC series are considered inhomogeneous (Bern, Neuchatel, La Chaux-de-Fons, Locarno and Chur). When a break is identified in the SD and TCC series, the series used to estimate the monthly adjustments are chosen among the 1-3 highest correlated series. A similar approach has been applied to the monthly clear-sky SD series, although corrections have not been applied due to the larger number of breaks detected in 6 series. Consequently, only a subset of 11 homogenous series is considered (see Table 1). Equally, the low number of stations with records before the 1930s forced us to limit the clear-sky SSR mean series to the 1931-2010 period. As a result of the strong spatial correlation in the SD series, with a subset of 11 series it is possible to capture the same interannual and decadal variability as using the 17 series (Fig. 1).

\section{Estimation of SSR using SD}

Although different methods are traditionally used to estimate SSR values using SD, most of them relate both variables site per site, normally implying one fit per station and temporal resolution. An individual fitting is more sensitive to inhomogeneities present in the series, as well as local peculiarities and noise. Therefore, in this study, a unique monthly equation for the whole of Switzerland has been obtained to convert SD records into SSR.

For the all-sky conditions, first the monthly anomalies (obtained as differences to the 1981-2010 mean) of all-sky SSR and all-sky SD were calculated for each of the 17 series. Mean anomalies series for the whole of Switzerland were computed by averaging the 17 anomaly series, which result in mean monthly anomalies series for SSR and SD. Then, for each month a linear regression is used to estimate the linear relationship between SSR (dependent variable) and SD (independent variable) during the common 1981-2010 period (Table 3 ). The correlation coefficients between the mean monthly series are highly significant $(\alpha<0.01)$ and range between 0.87 (February) and 0.98 (April, Fig. 2a), with an excellent fit between the values which are mostly close to the diagonal line. This implies that the SD monthly anoma-

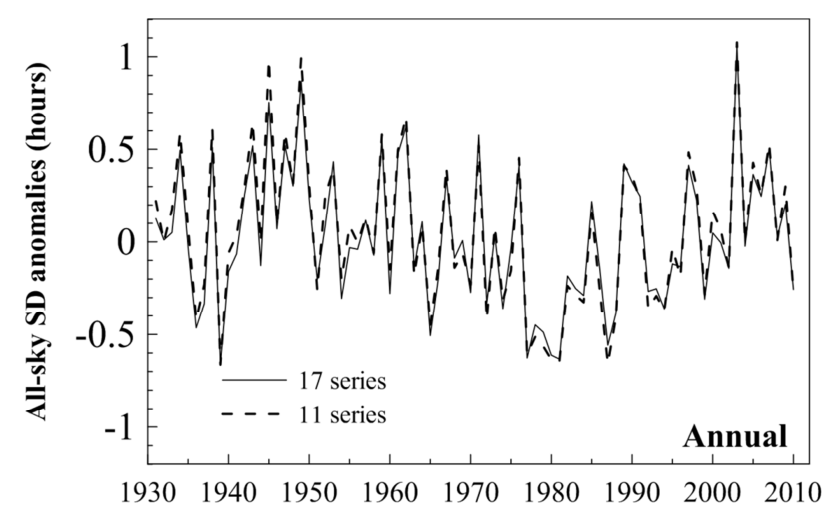

Fig. 1. Mean annual all-sky SD series from 1931 to 2010 in Switzerland, as computed using the 17 stations (solid line) and a subset of the 11 stations (shaded line) with collocated homogeneous clearsky SD series. Both annual series show a similar decadal variability and are highly correlated ( $r=0.99 \alpha<0.01,1931-2010$ period) at interannual timescales.

lies explain between $76 \%$ and $96 \%$ of the variability of the SSR monthly anomalies. In order to estimate the SSR monthly anomalies during the whole period, these linear regression equations are applied using as dependent variable the monthly mean SD anomalies available during the 18852010 period. A monthly root mean squared error (RMS) of $4.2 \mathrm{~W} \mathrm{~m}^{-2}$ is found between the estimated and observed SSR anomalies, in agreement with previous findings (e.g. Benson et al., 1984).

A similar approach has been applied for the clear-sky conditions, but only using the subset of 11 series previously described. Monthly anomalies of clear-sky SSR and SD at each station are computed using the mean for the same reference period (1981-2010). Again, a linear regression is used to estimate the relationship between both variables for each month during the common 1981-2010 period (Table 3). The correlation coefficients between both series range between 0.47 (April) and 0.80 (July, Fig. 2b), clearly significant but lower than for all-sky, showing a larger scatter in the data. The clear-sky SSR monthly anomalies during the whole period are estimated using these linear regression equations. As a consequence of this decrease in the strength of the relationships, the RMS $\left(5.5 \mathrm{~W} \mathrm{~m}^{-2}\right)$ between the estimated and observed clear-sky monthly anomalies is slightly higher than for all-sky SSR.

As a reference, the SSR and SD annual means estimated as an average of the 17 (11) series are $141.8 \mathrm{~W} \mathrm{~m}^{-2}$ $\left(197.2 \mathrm{~W} \mathrm{~m}^{-2}\right)$ and $4.8 \mathrm{~h}(9.8 \mathrm{~h})$ for all-sky (clear-sky) days, respectively. 
Table 3. Linear regression results for the Swiss mean monthly series, for all-sky and clear-sky SD (in hours) versus SSR (in $\mathrm{W} \mathrm{m}^{-2}$ ), over the period 1981-2010.

\begin{tabular}{lcccc}
\hline \multirow{2}{*}{ Month } & Equations & $r$ & Equations & $r$ \\
\cline { 2 - 5 } January & $s s r=6.95 s d+0.00$ & 0.93 & $s s r=9.59 s d+0.35$ & 0.65 \\
February & $s s r=8.46 s d-0.01$ & 0.88 & $s s r=13.37 s d+0.35$ & 0.63 \\
March & $s s r=11.42 s d+0.05$ & 0.95 & $s s r=16.89 s d+0.24$ & 0.79 \\
April & $s s r=15.25 s d+0.06$ & 0.98 & $s s r=10.10 s d+0.85$ & 0.47 \\
May & $s s r=15.14 s d+0.00$ & 0.96 & $s s r=14.28 s d+0.97$ & 0.60 \\
June & $s s r=14.73 s d+0.02$ & 0.94 & $s s r=9.75 s d+0.94$ & 0.61 \\
July & $s s r=14.62 s d+0.05$ & 0.95 & $s s r=17.46 s d+0.46$ & 0.80 \\
August & $s s r=12.59 s d-0.06$ & 0.94 & $s s r=17.87 s d+0.46$ & 0.66 \\
September & $s s r=12.41 s d+0.03$ & 0.96 & $s s r=17.80 s d+0.49$ & 0.79 \\
October & $s s r=11.14 s d+0.01$ & 0.96 & $s s r=17.02 s d+0.33$ & 0.69 \\
November & $s s r=7.29 s d+0.00$ & 0.93 & $s s r=13.79 s d+0.24$ & 0.77 \\
December & $s s r=5.59 s d+0.00$ & 0.87 & $s s r=4.37 s d+0.25$ & 0.49 \\
\hline
\end{tabular}

\section{Decadal variations and trends of the estimated SSR and TCC}

Annual and seasonal series were computed as an arithmetic mean of the 17 (11) monthly anomalies for all-sky SSR and TCC (clear-sky SSR) series, where the seasons are defined as spring (MAM), summer (JJA), autumn (SON), and winter (DJF). The use of the composite series enhances the signal-to-noise ratio, which permits a better identification of long-term trends. The linear trends of the series were calculated by means of least squares linear fitting and their significance estimated by the Mann-Kendall nonparametric test (e.g. Kendall, 1975; Sneyers, 1992). For all-sky SSR and TCC (clear-sky SSR) the linear trends are applied over the whole 1885-2010 (1931-2010) period, as well as different subperiods, which are shown in Table 4 (Table 5). In order to improve the visualization of the long-term and decadal variability, the mean series are plotted together with their 17-yr Gaussian low-pass filters (hereafter referred as 17GLPF) that only consider the values on one side at the start and end of the series in order to filter the full period.

Figure 3a shows the mean annual all-sky SSR series, together with the 17GLPF, over Switzerland during the period 1885-2010. The series starts with a slight decrease during the first two decades, followed by a period without relevant decadal variations between the early 1900s and the 1930s. Subsequently, the series shows a strong and brief increase in the 1940s and reaches a maximum at the beginning of the 1950s. Afterwards, there is a clear tendency towards a decrease until the early 1980s, with a clear change point in the series due to the very low values recorded in the 1977-1981 subperiod. Since the 1980 s there is a tendency to increase until the mid-2000s that compensates the previous decrease (with an absolute maximum in 2003), followed by a stabilization or slight decrease in the final years of the series. The linear trend, estimated over the whole $1885-2010$ period, is significant and slightly negative $\left(-0.24 \mathrm{~W} \mathrm{~m}^{-2}\right.$ per decade), although not significant for the most confident 1931-2010 a

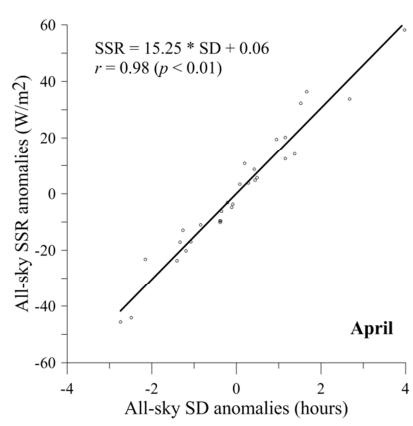

b

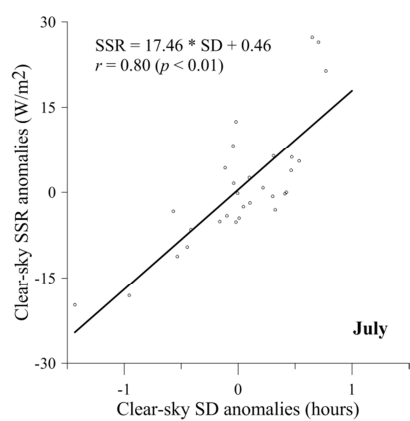

Fig. 2. Scatterplot of the mean monthly series in April for all-sky (a) and July for clear-sky (b) SSR versus SD in Switzerland during the 1981-2010 period. The anomalies are expressed as differences from the 1981-2010 mean, and the best fit line is indicated in each plot, together with their linear regression equations and correlation coefficients.

subperiod. If the analyzed period is subdivided in the 19511980 and 1981-2010 subperiods, the linear trends are significant negative $\left(-1.98 \mathrm{~W} \mathrm{~m}^{-2}\right.$ per decade $)$ and positive $(+2.44$ $\mathrm{W} \mathrm{m}^{-2}$ per decade), respectively.

Regarding the TCC series, the mean annual series (Fig. 3b) starts with a period without relevant decadal variations until the 1950s, followed by a strong increase in TCC during the 1950s-1980s period, in clear agreement with the observed decrease in all-sky SSR during the same years and the lack of variations in the previous decades. Subsequently, there is a slight decrease of TCC during the 1980s, followed by a period of stabilization until nowadays which does not compensate the previous increase. The overall linear trend of the annual TCC series during the whole $1885-2010$ period is positive and significant $(+0.51 \%$ per decade $)$, a rise that is mainly due to the strong increase detected in the 1951-1980s subperiod $(+1.79 \%$ per decade $)$. This annual TCC mean series is highly correlated with the annual all-sky SSR mean series $(r=-0.84 \alpha<0.01,1885-2010$ period) at interannual timescales. Meanwhile, the correlation is considerably lower if the smoothed series with the 17GLPF is considered ( $r=-0.66 \alpha<0.01,1885-2010$ period), which means a decrease in the agreement of both mean series in the lower frequency. This fact can be easily seen in Fig. 3c, where running correlations (window of $21 \mathrm{yr}$ ) are applied over the most confident 1931-2010 subperiod. The raw series tend always to have higher correlations than the smoothed series, especially after the 1970s when there is a clear disagreement between the trends of both variables. In fact, the TCC time evolution is in line (inverse relationship) with all-sky SSR during the 1880s-1970s period, and no longer afterwards when a major disagreement is observed between both series.

As far as seasonal mean series are concerned (Figs. 4 and 5, Table 4), all-sky SSR and TCC series in spring and summer show a similar decadal variation as the annual series 
Table 4. Annual and seasonal estimated SSR and TCC trends* (together with their standard deviation) in Switzerland over different subperiods.

\begin{tabular}{|c|c|c|c|c|c|c|c|c|c|c|}
\hline \multirow[t]{2}{*}{ Periods } & \multicolumn{2}{|c|}{ 1885-2010 } & \multicolumn{2}{|c|}{$1931-2010$} & \multicolumn{2}{|c|}{$1951-2010$} & \multicolumn{2}{|c|}{$1951-1980$} & \multicolumn{2}{|c|}{$1981-2010$} \\
\hline & SSR & $\mathrm{TCC}$ & SSR & $\mathrm{TCC}$ & SSR & $\mathrm{TCC}$ & SSR & $\mathrm{TCC}$ & SSR & TCC \\
\hline Annual & $-0.24 \pm 0.1$ & $+0.51 \pm 0.0$ & - & $+0.48 \pm 0.1$ & + & + & $-1.98 \pm 0.9$ & $+1.79 \pm 0.6$ & $+2.44 \pm 0.8$ & + \\
\hline Winter & + & $+0.39 \pm 0.1$ & $+0.37 \pm 0.2$ & - & $+0.34 \pm 0.2$ & - & - & + & + & - \\
\hline Spring & - & $+0.63 \pm 0.1$ & - & $+1.00 \pm 0.2$ & - & $+0.77 \pm 0.4$ & $-5.68 \pm 1.9$ & $+4.31 \pm 1.1$ & $+5.26 \pm 2.1$ & - \\
\hline Summer & $-0.87 \pm 0.2$ & $+0.68 \pm 0.1$ & - & $+0.68 \pm 0.2$ & + & + & - & + & + & + \\
\hline Autumn & + & $+0.31 \pm 0.1$ & + & + & - & $+0.79 \pm 0.4$ & + & + & + & + \\
\hline
\end{tabular}

* Values are expressed as $\mathrm{W} \mathrm{m}^{-2}$ and \% per decade, respectively. Bold, italic and regular values indicate trends with significance level higher than $99 \%, 95 \%$ and $90 \%$, respectively. For lower levels of significance only the sign of the trend is indicated.

Table 5. As Table 1, But For Estimated Clear-sky SSR Series.

\begin{tabular}{llllll}
\hline Periods & $1931-2010$ & $1931-1980$ & $1951-2010$ & $1951-1980$ & $1981-2010$ \\
\hline Annual & $+0.17 \pm 0.1$ & - & $+\mathbf{0 . 5 3} \pm \mathbf{0 . 2}$ & - & $\mathbf{+ 2 . 6 8} \pm \mathbf{0 . 4}$ \\
Winter & $\mathbf{+ 0 . 4 9} \pm \mathbf{0 . 1}$ & + & $\mathbf{0 . 6 1} \pm \mathbf{0 . 2}$ & - & $+1.17 \pm 0.5$ \\
Spring & $\mathbf{+ 0 . 4 9} \pm \mathbf{0 . 2}$ & - & $+\mathbf{1 . 3 2} \pm \mathbf{0 . 3}$ & + & $+\mathbf{3 . 4 2} \pm \mathbf{0 . 9}$ \\
Summer & - & - & - & - & $+\mathbf{4 . 5 6} \pm \mathbf{0 . 8}$ \\
Autumn & + & - & $+0.58 \pm 0.2$ & - & $+1.55 \pm 0.8$ \\
\hline
\end{tabular}

previously described. This agreement is still more clear in spring, with a positive trend in TCC during the whole 18852010 period $(+0.63 \%$ per decade $)$ that is mainly due to the strong increase in the 1951-1980s subperiod $(+4.31 \%$ per decade) and no significant trend during the 1981-2010 subperiod. Instead, spring all-sky SSR show no significant trends during the whole period, with a strong decrease $\left(-5.68 \mathrm{~W} \mathrm{~m}^{-2}\right.$ per decade $)$ and increase $\left(+5.26 \mathrm{~W} \mathrm{~m}^{-2}\right.$ per decade) over the 1951-1980 and 1981-2010 subperiods, respectively. Finally, the all-sky SSR and TCC series in winter and autumn are the most stable, although for the former an intriguing significant increase $\left(+0.37 \mathrm{~W} \mathrm{~m}^{-2}\right.$ per decade) in all-sky SSR is observed if the 1931-2010 period is considered, without significant decadal variations (dimming/brightening periods) observed since the 1950s.

Regarding clear-sky SSR, Fig. 6 shows the mean annual series in Switzerland over the 1931-2010 period, whereas annual linear trends estimated over the whole period and different subperiods are shown in Table 5. The most interesting feature of clear-sky SSR is the positive and significant trend $\left(+0.17 \mathrm{~W} \mathrm{~m}^{-2}\right.$ per decade) found in the annual series over the complete 1931-2010 period. This trend is mainly due to a slight increase between the 1930s and 1950s and a strong increase since the $1980 \mathrm{~s}$, with only a period of decrease in the 1960s-1970s period. Interesting features are the two clear minima anomalies observed in 1983 and 1992, which should be the signal of the El Chichón (April 1982) and Pinatubo (June 1991) volcanic eruptions that occurred one year before. This decrease might be the consequence of the direct effect (scattering of the shortwave radiation) of the volcanic sulfur aerosols released by these volcanic eruptions, the largest recorded in the 1931-2010 period.
The seasonal clear-sky SSR time series (Fig. 6, Table 5) show a similar shape, although with some interesting features. Winter and spring show the strongest increases $\left(+0.49 \mathrm{~W} \mathrm{~m}^{-2}\right.$ per decade) during the whole analyzed period, and spring $\left(+3.42 \mathrm{~W} \mathrm{~m}^{-2}\right.$ per decade $)$ and summer $\left(+4.56 \mathrm{~W} \mathrm{~m}^{-2}\right.$ per decade) if the trends are restricted to the 1981-2010 period. Equally, the low anomalies due to the volcanic eruptions are clearer in the spring and summer series, with lower anomalies in summer during the El Chichón eruption, as compared to the Pinatubo, as previously reported in Spain (Sanchez-Lorenzo et al., 2007, 2009).

\section{Discussion and conclusions}

It has been shown that sunshine duration (SD) records can be considered as an excellent proxy to estimate all-sky and clear-sky surface solar radiation (SSR) variations over regions such as Switzerland, for more than a century, which can help to reduce some of the open issues in the dimming/brightening phenomenon.

Specifically, in this study, a general tendency towards a decrease in the estimated all-sky SSR over Switzerland is observed when data since late 19th century is considered. Similar findings were obtained by Rebetez and Beniston (1998), but only using SD records of 4 stations during the 19011996 period. Equally, the present study confirms a dimming/brightening since the 1950 s in the mean annual estimated all-sky SSR series, using a higher density of stations than other studies, which provides a more robust climate signal, in general agreement with the observed worldwide trends in SSR (Wild, 2009, 2012). If seasonal series are 
a)

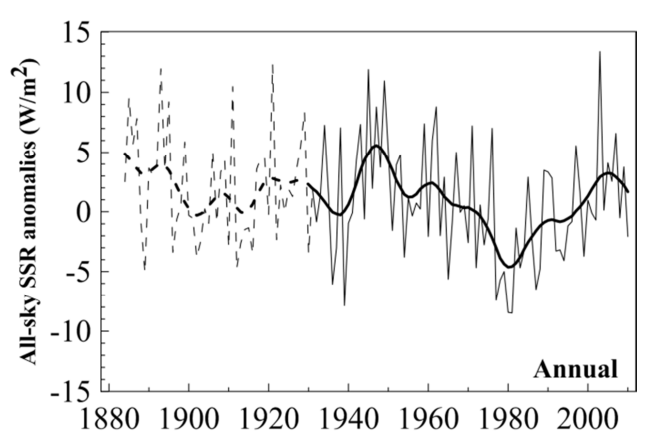

b)

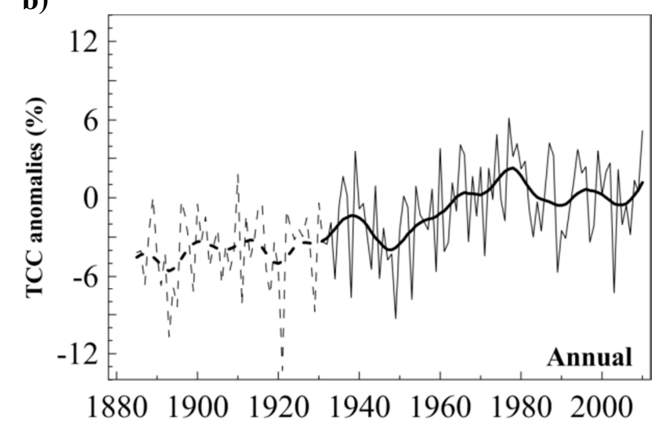

c)

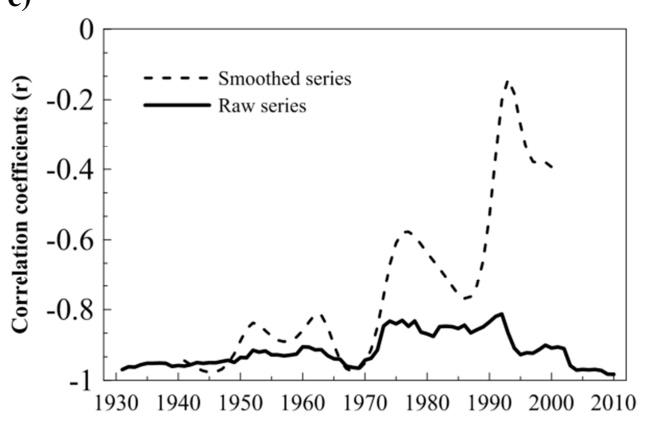

Fig. 3. Mean annual all-sky SSR (a) and TCC (b) series (thin line) from 1885 to 2010 for all 17 stations in Switzerland, plotted together with the 17-yr Gaussian low-pass filter (thick line). The series are expressed as anomalies from the 1981-2010 mean. Dashed lines are used before 1931 due to the lower confidence in this period. (c) Annual running correlations with time windows of $21 \mathrm{yr}$ between the raw and smoothed time series using a 17-yr Gaussian low-pass filter during the most confident 1931-2010 period.

considered, spring and summer show the most similar features to the annual series, as has been previously described in other parts of Europe (Chiacchio and Wild, 2010). These results are also in line with the SD trends reported for Western Europe (Sanchez-Lorenzo et al., 2008) and the Alpine region (Brunetti et al., 2009), although here we showed these changes quantified as energy fluxes for the first time.

Interestingly, TCC seems to explain the major part of the decadal variability observed in all-sky SSR over Switzerland

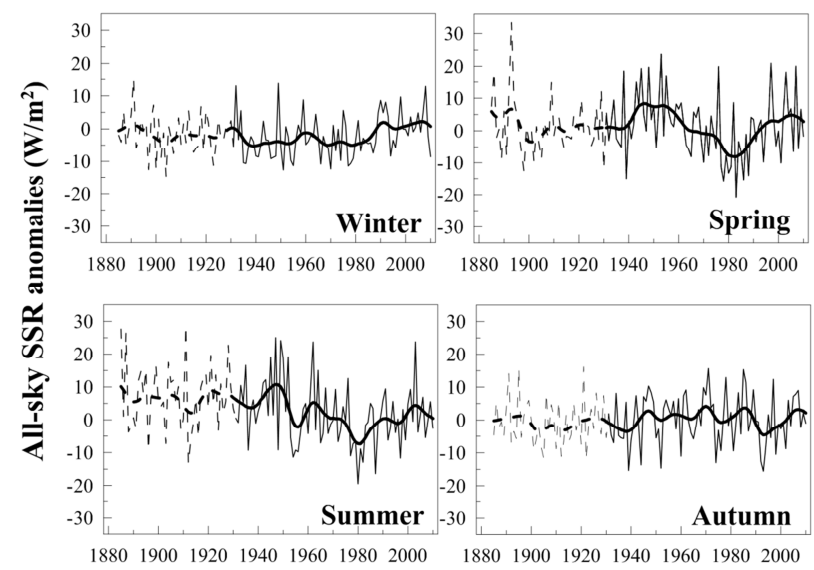

Fig. 4. Mean seasonal all-sky SSR series (thin line) from 1885 to 2010 in Switzerland, plotted together with a 17-yr Gaussian lowpass filter (thick line). The series are expressed as anomalies from the 1981-2010 mean. Dashed lines are used before 1931 due to the lower confidence of the previous period.

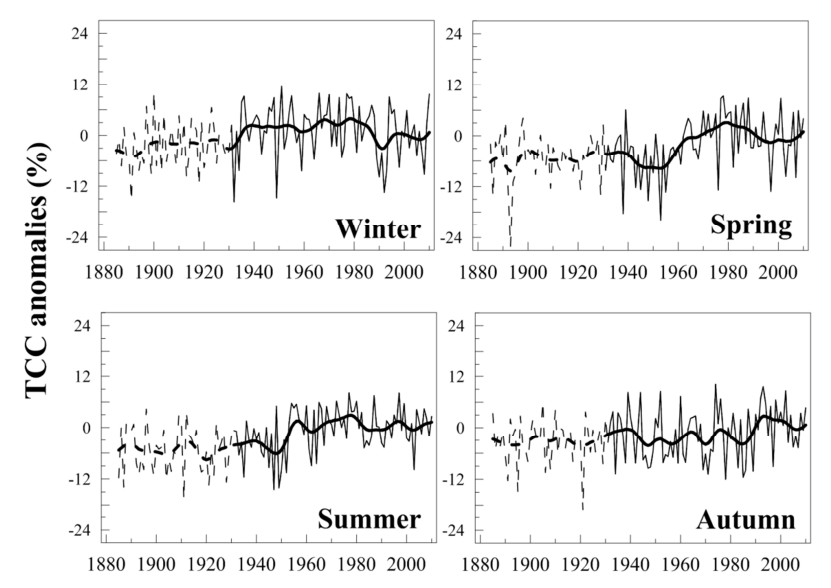

Fig. 5. Mean seasonal series (thin line) for total cloud cover (TCC) from 1885 to 2010 in Switzerland, plotted together with a 17-yr Gaussian low-pass filter (thick line). The series are expressed as anomalies from the 1981-2010 mean. Dashed lines are use before 1931 due to the lower confidence of the previous period.

until the early 1980s, including the clear dimming period observed between the 1950s and 1970s. Afterwards, trends in both variables are in disagreement and a different cause is needed to explain the strong brightening detected between the 1980s and 2000s.

The most plausible reason for this disagreement might be also the cause of the trends in clear-sky SSR series, also derived for the first time by means of SD records. These series show significant positive trends during the 1981-2010 subperiod, especially in spring and summer, and a decrease (statistically non-significant) in the 1951-1980 period where a significant decrease is observed in all-sky SSR. 

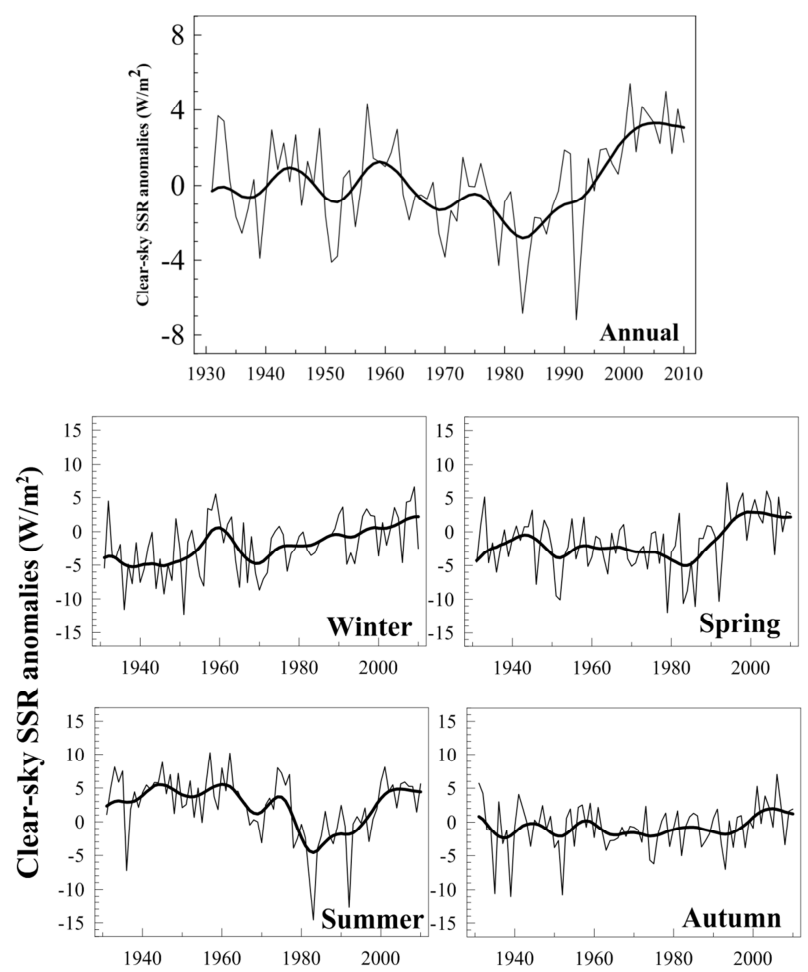

Fig. 6. Mean annual and seasonal clear-sky SSR series (thin line) in Switzerland, plotted together with the 17-yr Gaussian low-pass filter (thick line). The series are expressed as anomalies from the 1981-2010 mean. A subset of the 11 stations with more reliable SD and TCC daily is used to produce the mean time series, which only is plotted for the 1931-2010 period due to the low number of stations with records before the 1930s.

These trends reported in estimated clear-sky SSR during 1981-2010 should be primarily caused by the direct aerosol effect, as pointed out by previous studies using observed clear-sky SSR fluxes (Ruckstuhl et al., 2008; Ruckstuhl and Norris, 2009; Folini and Wild, 2011). In fact, it has been previously suggested that $\mathrm{SD}$ records can be useful to detect a decrease in the solar beam due to the increase of the atmospheric aerosols, especially during sunrises and sunsets with long travelling paths through the atmosphere (e.g. Helmes and Jaenicke, 1984; Horseman et al., 2008; Sanchez-Lorenzo et al., 2009; Xia, 2010; Wang et al., 2012). This assumption is reinforced by the strong decrease found in the estimated clear-sky SSR anomalies after the El Chichón and Pinatubo volcanic eruptions, mainly as a possible consequence of the large increase of sulfate aerosols in the lower stratosphere. Thus, clear-sky SSR estimations using SD records seem to be a useful tool to detect changes in the atmospheric aerosol concentrations.

Moreover, the reconstructed clear-sky SSR shows a general agreement with the trend estimations during the last decades found in other studies. Here we report a significant increase of $+2.68 \mathrm{~W} \mathrm{~m}^{-2}$ per decade during the 1981-2010 period, slightly higher than the reported trends in Switzerland by Ruckstuhl and Norris (2009) $\left(+1.8 \mathrm{~W} \mathrm{~m}^{-2}\right.$ per decade). The difference can be due to the different methods used to derive clear-sky SSR, the number of surface stations or the time period considered. In fact, Ruckstuhl and Norris (2009) found a much higher significant increase $\left(+3.5 \mathrm{~W} \mathrm{~m}^{-2}\right.$ per decade) in clear-sky SSR series when they applied their analyses to stations in northern Germany. Norris and Wild (2007) estimated a widespread increase in clear-sky SSR over whole Europe around $+2.0-2.3 \mathrm{~W} \mathrm{~m}^{-2}$ per decade, which is in good agreement with the present study.

The lack of statistical significance in the decrease seen in clear-sky SSR series during the 1951-1980 period is in line with the results found by Liepert (1997) in Germany, and suggest a less obvious role of the direct aerosol effects in the all-sky SSR decrease found in Switzerland during this period. Consequently, the detected increase in TCC is the most important contributor to the decrease in all-sky SSR, although in the current study it is not possible to distinguish if this increase is due to natural variability or an anthropogenic indirect aerosol effect on clouds.

Moreover, an early brightening (Ohmura, 2009; Wild, 2009) has been identified over Europe at a few sites with SSR records available during the 1930s-1950s period, which has also been observed using SD records in Western Europe (Sanchez-Lorenzo et al., 2008). This possible increase in SSR before the 1950s is inconsistent with climate model simulations during this time period that show a decrease in SSR (Romanou et al., 2007). Nevertheless, the present study shows no evidence of a possible early brightening in all-sky SSR from late 19th century to the 1950s in Switzerland, but still a sharp increase in the 1940s. On the other hand, the clear-sky SSR series show a slight increase during the 1930s1950s period. This observed increase in clear-sky SSR before the 1950s is in agreement with the increase reported in allsky SSR and SD in other locations over Europe, as previously detailed. Although there is no current explanation for this increase in clear-sky SSR during this period, a possible cause can be the observed decrease in industrial black carbon emissions during the first half of the 20th century (McConnell et al., 2007), as a results of a coal to gas transition in the production of energy. Further research is needed in order to confirm this hypothesis, but is beyond the scope of this article.

Briefly, the conclusions of our study can be summarized as:

1. SD can be considered as an excellent proxy to estimate quantitatively all-sky and clear-sky SSR trends from the late 19th century up to the present.

2. Estimated all-sky SSR trends show a general agreement with cloud cover variability before the 1980s over Switzerland; at this point, a discrepancy in the sign of the trend is visible in the series. 
3. A dimming (brightening) is clearly visible in all-sky SSR during the 1950s-1970s (1980s-2000s) subperiod, in line with previous studies that used a lower density of stations. Equally, there is a brief early brightening period in Switzerland restricted to the 1940s, with a lack of significant decadal variations in the preceding period.

4. Estimated clear-sky SSR provides evidence for the existence of periods where SSR over Switzerland is unrelated to TCC variations, particularly in the most recent parts of the records, which are possibly linked to changes in aerosol concentrations in the atmosphere. Further research is needed to confirm the reliability of these estimated clear-sky SSR over other areas of the world.

Acknowledgements. The first author was supported by a postdoctoral fellowship from the "Comissionat per a Universitats $\mathrm{i}$ Recerca del Departament d'Innovació, Universitats i Empresa de la Generalitat de Catalunya" (2009 BP-A 00035). We thank MeteoSwiss for providing the data set, to Laurent Vuilleumier for facilitating information about sunshine duration and cloud cover observations in Switzerland and Christoph Schaer for the continuous support of our work. Dimming/brightening research at ETH is supported by the National Centre for Competence in Climate Research (NCCR Climate) of the Swiss National Science Foundation.

Edited by: K. Carslaw

\section{References}

Alexandersson, H. and Moberg, A.: Homogenization of Swedish temperature data. Part I: Homogeneity test for linear trends, Int. J. Climatol, 17, 25-34, 1997.

Auer, I., Böhm, R., Jurkovic, A., Lipa, W., Orlik, A., Potzmann, R., Schöner, W., Ungersböck, M., Matulla, C., Briffa, K., Jones, P., Efthymiadis, D., Brunetti, M., Nanni, T., Maugeri, M., Mercalli, L., Mestre, O., Moisselin, J.-M., Begert, M., M “ullerWestermeier, G., Kveton, V., Bochnicek, O., Stastny, P., Lapin, M., Szalai, S., Szentimrey, T., Cegnar, T., Dolinar, M., GajicCapka, M., Zaninovic, K., Majstorovic, Z., and Nieplova, E.: HISTALP-Historical instrumental climatological surface time series of the Greater Alpine Region, Int. J. Climatol., 27, 17-46, 2007.

Baumgartner, T.: Die Schwellenintensität des Sonnenscheinautographen campbell-stokes an wolkenlosen Tagen. Arbeitsberichte der Schweizerischen Meteorologischen Zentralanstalt, Nr. 84, Zürich, 1979.

Benson, R. B., Paris, M. V., Sherry, J. E., and Justus, C. G.: Estimation of daily and monthly direct, diffuse and global solar radiation from sunshine duration measurements, Sol. Energy, 32, 523-535, 1984.

Brunetti, M., Lentini, G., Maugeri, M., Nanni, T., Auer, I., Böhm, R., and Schöner, W. : Climate variability and change in the Greater Alpine Region over the last two centuries based on multivariable analysis, Int. J. Climatol., 19, 2197-2225, 2009.
Cermak, J., Wild, M., Knutti, R., Mishchenko, M. I., and Heidinger, A. K.: Consistency of global satellite-derived aerosol and cloud data sets with recent brightening observations, Geophys. Res. Lett., 37, L21704, doi:10.1029/2010GL044632, 2010.

Chiacchio, M. and Wild, M.: Influence of NAO and clouds on longterm seasonal variations of surface solar radiation in Europe, J. Geophys. Res., 115, D00D22, doi:10.1029/2009JD012182, 2010.

Folini, D. and Wild, M.: Aerosol emissions and dimming/brightening in Europe: Sensitivity studies with ECHAM5-HAM, J. Geophys. Res., 116, D21104, doi:10.1029/2011JD016227, 2011.

Gilgen, H., Wild, M., and Ohmura, A.: Means and trends of shortwave irradiance at the surface estimated from GEBA, J. Clim., 11, 2042-2061, 1998.

Helmes, L. and Jaenicke, R.: Experimental verification of the determination of atmospheric turbidity from sunshine recorders, J. Clim. Appl. Meteorol., 23, 1350-1353, 1984.

Horseman, A., Mackenzie, A. R., and Timmis, R.: Using bright sunshine at low-elevation angles to compile an historical record of the effect of aerosol on incoming solar radiation, Atmos. Environ., 42, 7600-7610, 2008.

Kaiser, D. P.: Decreasing cloudiness over China: An updated analysis examining additional variables, Geophys. Res. Lett., 27, 2193-2196, doi:10.1029/2000GL011358, 2000.

Kendall, M. G.: Rank Correlation Methods. Griffin, London, 1975.

Liepert, B.: Recent changes in solar radiation under cloudy conditions in Germany, Int. J. Climatol., 17, 1581-1593, 1997.

Liepert, B.: Observed reductions of surface solar radiation at sites in the United States and worldwide from 1961 to 1990, Geophys. Res. Lett., 29, 1421, doi:10.1029/2002g1014910, 2002.

Lindfors, A. and Vuilleumier, L.: Erythemal UV at Davos (Switzerland), 1926-2003, estimated using total ozone, sunshine duration, and snow depth, J. Geophys. Res., 110, D02104, doi:10.1029/2004JD005231, 2005.

Major, J.: Radiation and sunshine duration measurements. Comparison of pyranometers and electronic sunshine duration recorders of RA VI Budapest, July-December 1984, Instruments and Observing Methods, Report No. 16, World Meteorological Organization, 36 pp., 1986.

McConnell, J. R., Edwards, R., Kok, G. L., Flanner, M. G., Zender, C. S., Satzman, E. S., Banta, J. R., Pasteris, D. R., Carter, M. M., and Kahl, J. D. W.: 20th-century industrial black carbon emissions altered arctic climate forcing, Science, 317, 1381-1384, 2007.

Norris, J. R. and Wild, M.: Trends in aerosol radiative effects over Europe inferred from observed cloud cover, solar "dimming," and solar“brightening”, J. Geophys. Res., 112, D08214, doi:10.1029/2006JD007794, 2007.

Norris, J. R. and Wild, M.: Trends in aerosol radiative effects over China and Japan inferred from observed cloud cover, solar "dimming," and solar "brightening," J. Geophys. Res., 114, D00D15, doi:10.1029/2008JD011378, 2009.

Ohmura, A.: Observed decadal variations in surface solar radiation and their causes, J. Geophys. Res., 114, D00D05, doi:10.1029/2008JD011290, 2009.

Ohmura, A. and Lang, H.: Secular variations of global radiation in Europe, in: IRS '88: Current Problems in Atmospheric Radiation, edited by: Leonoble, J. and Geleyn, J. F., A. Deepak Publ., 
Hampton, 298-301, 1989.

Pallé, E. and Butler, C. J.: Sunshine records from Ireland: Cloud factors and possible links to solar activity and cosmic rays, Int. J. Climatol., 21, 709-729, 2001.

Pallé, E. and Butler, C. J.: Comparison of sunshine records and synoptic cloud observations: a case study for Ireland, Phy. Chem. Earth, 27, 405-414, 2002.

Philipona, R., Behrens, K., and Ruckstuhl, C.: How declining aerosols and rising greenhouse gases forced rapid warming in Europe since the 1980s, Geophys. Res. Lett., 36, L02806, doi:10.1029/2008GL036350, 2009.

Rebetez, M. and Beniston, M.: Changes in sunshine duration are correlated with changes in daily temperature range this century: An analysis of Swiss climatological data, Geophys. Res. Lett., 25, 3611-3613, doi:10.1029/98GL02810, 1998.

Romanou, A., Liepert, B., Schmidt, G. A, Rossow, W. B., Ruedy, R. A., and Zhang, Y.: 20th century changes in surface solar irradiance in simulations and observations, Geophys. Res. Lett., 34, L05713, doi:10.1029/2006GL028356, 2007.

Ruckstuhl, C. and Norris, J. R.: How do aerosol histories affect solar "dimming" and "brightening" over Europe?: IPCC-AR4 models versus observations, J. Geophys. Res., 114, D00D04, doi:10.1029/2008JD011066, 2009.

Ruckstuhl, C., Philipona, R., Behrens, K., Collaud Coen, M., Dürr, B., Heimo, A., Mätzler, C., Nyeki, S., Ohmura, A., Vuilleumier, L., Weller, M., Wehrli, C., and Zelenka, A.: Aerosol and cloud effects on solar brightening and the recent rapid warming, Geophys. Res. Lett., 35, L12708, doi:10.1029/2008GL034228, 2008.

Sanchez-Lorenzo, A., Brunetti, M., Calbó, J., and Martin-Vide, J.: Recent spatial and temporal variability and trends of sunshine duration over the Iberian Peninsula from a homogenized data set, J. Geophys. Res., 112, D20115, doi:10.1029/2007JD008677, 2007.

Sanchez-Lorenzo, A., Calbó, J., and Martin-Vide, J.: Time evolution of sunshine duration over western Europe (1938-2004), J. Clim., 21, 6089-6098, 2008.

Sanchez-Lorenzo, A., Calbó, J., Brunetti, M., and Deser, C.: Dimming/brightening over the Iberian Peninsula: Trends in sunshine duration and cloud cover and their relations with atmospheric circulation, J. Geophys. Res., 114, D00D09, doi:10.1029/2008JD011394, 2009.

Sanchez-Lorenzo, A., Guijarro, J.A., Brunetti, M., and Wild, M.: Towards a homogenization of the long-term surface solar global radiation series over Europe, Geophys. Res. Abstr., 13, EGU2011-1300-1, available at: http://meetingorganizer. copernicus.org/EGU2011/EGU2011-1300-1.pdf, 2011.

Sanchez-Lorenzo, A., Calbó, J., and Wild, M.: Increasing cloud cover in the 20th century: review and new findings in Spain, Clim. Past, 8, 1199-1212, doi:10.5194/cp-8-1199-2012, 2012.

Shi, G.-Y., Hayasaka, T., Ohmura, A., Chen, Z. H., Wang, B., Zhao, J.-Q., Che, H.-Z., and Xu, L.: Data quality assessment and the long-term trend of ground solar radiation in China, J. Appl. Meteorol. Climatol., 47, 1006-1016, 2008.

Sneyers, R.: On the use of statistical analysis for the objective determination of climatic change, Meteorol. Z., 1, 247-256, 1992.
Stanhill, G.: Estimation of direct solar beam irradiance from measurements of the duration of bright sunshine, Int. J. Climatol., 18, 347-354, 1998.

Stanhill, G.: Through a glass brightly: Some new light on the Campbell Stokes sunshine recorder, Weather, 58, 3-11, 2003.

Stanhill, G.: The role of water vapor and solar radiation in determining temperature changes and trends measured at Armagh, 1881-2000, J. Geophys. Res., 116, D03105, doi:10.1029/2010JD014044, 2011.

Stanhill, G. and Cohen, S.: Global dimming: A review of the evidence for a widespread and significant reduction in global radiation, Agr. Forest Meteorol., 107, 255-278, 2001.

Stanhill, G. and Cohen, S.: Solar radiation changes in the United States during the twentieth century: Evidence from sunshine duration measurements, J. Clim., 18 , 1503-1512, 2005.

Stanhill, G. and Cohen, S.: Solar radiation changes in Japan during the 20th century: Evidence from sunshine duration measurements, J. Meteorol. Soc. Jpn., 86, 57-76, 2008.

Streets, D. G., Wu, Y, and Chin, M.: Two-decadal aerosol trends as a likely explanation of the global dimming/brightening transition, Geophys. Res. Lett., 33, L15806, doi:10.1029/2006GL026471, 2006.

Tang, W.-J., Yang, K., Qin, J., Cheng, C. C. K., and He, J.: Solar radiation trend across China in recent decades: a revisit with quality-controlled data, Atmos. Chem. Phys., 11, 393-406, doi:10.5194/acp-11-393-2011, 2011.

Trenberth, K. E., Jones, P. D., Ambenie, P., Bojariu, R., Easterling, D., Klein Tank, A., Parker, D., Rahimzadeh, F., Renwick, J. A., Rusticucci, M., Soden, B., and Zhai, P.: Observations: Surface and Atmospheric Climate Change, in: Climate Change 2007: The Physical Science Basis. Contribution of the Working Group I to the Fourth Assessment Report of the IPCC, edited by: Solomon, S., Qin, D., Manning, M., Chen, Z., Marquis, M., Averyt, K., Tignor, M., and Miller, H., Cambridge University Press, Cambridge, UK and New York, NY, USA, 2007.

Wang, Y., Yang, Y., Zhao, N., Liu, C., and Wang, Q.: The magnitude of the effect of air pollution on sunshine hours in China, J. Geophys. Res., 117, D00V14, doi:10.1029/2011JD016753, 2012.

Wild, M.: Global dimming and brightening: A review, J. Geophys. Res., 114, D00D16, doi:10.1029/2008JD011470, 2009.

Wild, M.: Enlightening global dimming and brightening, B. Am. Meteor. Soc., 93, 27-37, 2012.

Wild, M., Gilgen, H., Roesch, A., Ohmura, A., Long, C. N., Dutton, E. G., Forgan, B., Kallis, A., Russak, V., and Tsvetkov, A.: From dimming to brightening: Decadal changes in surface solar radiation, Science, 308, 847-850, doi:10.1126/science.1103215, 2005.

Xia, X.: Spatiotemporal changes in sunshine duration and cloud amount as well as their relationship in China during 1954-2005, J. Geophys. Res., 115, D00K06, doi:10.1029/2009JD012879, 2010. 